УДК 37.013

13.00.00 Педагогические науки

ДУХОВНЫЕ И НРАВСТВЕННЫЕ ЦЕННОСТИ В ПЕДАГОГИЧЕСКОМ КОНТЕКСТЕ КАК ИСТОЧНИК СОЗИДАТЕЛЬНОЙ ДЕЯТЕЛЬНОСТИ ЧЕЛОВЕКА

Козлова Тамара Андреевна канд. пед. наук, доцент каф. общей и социальной педагогики РИНЦ SPIN-код: 9693-9994 t.dekan2010@yandex.ru

Воронежский государственный педагогический университет, Воронеж, Россия

В повестке дня современной действительности все актуальнее становится тема воспитания.

Воспитание личности в любую эпоху притягивало к себе внимание. В статье автор размышляет над составляющими личности: духовность и нравственность, их соотношением. Так же автор исходит из того, что источник созидательной деятельности человека заложен в его духовных и нравственных ценностях

Ключевые слова: ВОСПИТАНИЕ, ДУХОВНОСТЬ, НРАВСТВЕННОСТЬ, ИДЕНТИЧНОСТЬ, СРЕДА, СОЦИАЛИЗАЦИЯ, ЦЕННОСТИ, СОВЕСТЬ
UDC 37.013

Pedagogical sciences

\section{SPIRITUAL AND MORAL VALUES IN THE PEDAGOGICAL CONTEXT AS THE SOURCE OF HUMAN CREATIVE ACTIVITY}

\author{
Kozlova Tamara Andreevna \\ Candidate in Pedagogy, associate professor of general \\ and social pedagogy \\ SPIN-code: 9693-9994 \\ t.dekan2010@yandex.ru \\ Voronezh State Pedagogical University, Voronezh, \\ Russia
}

The subject of upbringing is becoming more urgent in the agenda of modern reality. Upbringing of the individual has always attracted attention. In the article, the author reflects on the components of personality: spirituality and morality, their relation. The author also proceeds from the thought that the source of man's creative activity is laid in his spiritual and moral values

Keywords: UPBRINGING, SPIRITUALITY, MORALITY, IDENTITY, ENVIRONMENT, SOCIALIZATION, VALUES, CONSCIENCE

Doi: 10.21515/1990-4665-130-014

Key words: education, spirituality, morality, identity, environment, socialization, values, conscience.

Abstract: the agenda of contemporary reality is becoming increasingly relevant theme of education. Education of the individual in any era attracted attention. In the article the author reflects on the components of personality: spirituality and morality, and their ratio. The same author believes that the source of the creative activity of man inherent in his spiritual and moral values.

В современной действительности мы отмечаем пробуждение интереса к проблемам духовно - нравственного воспитания, к культуре российского народа. Человек становится центром внимания, как со стороны государства, так и Православной Церкви. Проблемы духовнонравственного воспитания рассматривались в исследованиях таких 
педагогов, психологов, философов, как В.А. Беляевой, Н.А. Бердяева, П.П. Блонского, В.П. Вахтерова, К.Н. Вентцеля, И.А. Ильина, П.Ф. Каптерева, П.Ф. Лесгафта, Н.И. Пирогова, М.М. Рубинштейна, К.Д. Ушинского и др.

Сегодня предпринимаются попытки рассмотреть образовательный процесс в контексте его целостности и современности. Современная парадигма образования продиктовала требования не только к организации образовательного процесса, но и к подготовке учителя, к его компетенциям. Особенность нововведений по нашему мнению выражается в том, что они связаны с возрождением духовной, нравственной культуры в контексте отечественного образования.

На протяжении жизнедеятельности человека, воспитание как в теоретическом, так и практическом плане рассматривало различные подходы и процессы к развитию личности. Задачи воспитания связаны со временем, с процессами развития общества. Сегодня можно утверждать, что наиболее актуальными вопросами в наше время в теории воспитания являются: индивидуальное и социальное воспитание. Особенности индивидуального воспитания и социального воспитания заключаются по нашему мнению, прежде всего в психолого - педагогической поддержке.

Жизнь настольно многообразна, и от того насколько человек овладеет опытом, освоит формы бытия, духовные и нравственные ценности, настолько будет выполнима им миссия на Земле.

Решая задачу социализации обучающихся, следует помнить о том, что в основе данного процесса должно лежать индивидуальное воспитание сообразно с природными, возрастными и индивидуальными особенностями. Иначе социализация личности (без учета индивидуальной составляющей) поглотит человека, его индивидуальность; будет утрачена его экзистенцианальность. И в тоже время не следует абсолютизировать индивидуальное воспитание личности, т.к. это может привести к искажению социальной составляющей личности. Воспитание, 
ориентированное только на развитие индивидуальной личности будет не только искажать ее социализацию, но и наносить вред как социуму, так и самой личности. «Я» будет доминировать над коллективом, и личность будет не в состоянии воспринимать окружающих (их боль, страдания, радость и т.п.). Поэтому личность будет успешной в том случае, если воспитание будет включать в себя и индивидуальную и социальную компоненты.

Выделим основные составляющие успешности личности:

- личностно социальная идентификация;

- освоение образа жизни в разные периоды своего развития;

- самореализация в профессиональной сфере, в личностной, в семейной;

- осознание себя субъектом, гражданином своего Отечества, мира;

- духовное самоопределение и самоактуализация и др.

В наше время мы наблюдаем обнищание человека в духовной и нравственной составляющих его. Происходит как бы замыкание личности на себе, своей жизнедеятельности, самоутверждении и т.п. за счет отстранения от других людей, от творения на благо общества, от созидания общего, от культурно - исторических истоков, что в будущем приводит к потере смысла жизни. С.А. Домусчи, священник пишет, что на нравственное состояние современного человека оказывают влияние и социальная автомизация, приводящая к обособлению от общества, и массовая культура, приводящая к все большей зависимости от навязываемых стереотипов[3].

Стремление к материальному благосостоянию, сребролюбию, сластолюбию, все более заполняет жизнь молодых людей и тем самым негативно сказывается на их духовном, социальном становлении и развитии. Поэтому педагогам все сложнее заниматься воспитанием подростков и молодежи. Процесс воспитания осложняется, что педагогическая деятельность должна включать одновременно как 
дифференцированный, так и интегрированный подходы, а так же личностный, индивидуальный и др. исходя из гуманистической парадигмы образования.

В центре внимания гуманитарной педагогики стоит человек, его творческие возможности и способности. И задача преподавателя раскрыть эти самые возможности и способности учащегося; создать условия для самореализации, самоутверждения и в целом для социализации в обществе. Нас окружает множество людей со своими интересами, возможностями, желаниями, интересами, и насколько они будут гуманными или эгоистичными зависит от той среды, которую создают родители, педагогическая общественность, взрослые и т.д. От того насколько какие ценности будут заложены в воспитанника, настолько будет его жизнеопределение в добре и зле. Поэтому считаем важным принципом воспитательного взаимодействия, это принцип культуросообразности. Через постижение ценностей и норм конкретной национальной и региональной культуры.

Принцип культуросообразности предполагает приобщение человека к различным ценностям культуры этноса, общества, цивилизации в целом; к культуре бытовой, материальной, производственной, духовной, религиозной, интеллектуальной, нравственной (определяющей отношения к природе, социуму, людям, к самому себе). Отсюда и соответствующие методы, формы воспитательного процесса.

В современных условиях зачастую изменения в социуме оказываются не только безуспешными, но и бессмысленными, если они не находят опору в духовно-нравственной жизни индивида, не подкрепляются адекватными изменениями в культуре, в образовании [5]. В основе воспитания личности должны лежат духовные, нравственные ценности, что будет способствовать ее активности в среде, в самореализации, в самосовершенствовании и т.д. Без духовной, 
нравственной составляющей, нет личности, следовательно и активной гражданской позиции.

Обращаясь к философско - культурному, педагогическому наследию, нельзя не обратить внимание, на такое понятие как «среда», ее сущность и влияние на личность. Теорию средового подхода разработал Ю.С. Мануйлов. Именно в среде происходит развитие образование человека. В то же время следует указать на то, что личность так же оказывает влияние на среду. Поэтому среда не будет стабильной. И значение среды в воспитании нельзя отрицать, как отмечают ученые - исследователи, занимающиеся проблемами воспитания (Б.Н.Алмазов, В.Г.Бочарова, Ю.С.Бродский, Е.П. Белозерцев, 3.А.Галагузова, А.В.Мудрик, В.Д.Семенов, В.А.Сластенин, и др.). введенные в действие ФГОС отражают создание образовательной среды как в обучении, воспитании, так и в целом в образовательном учреждении. И здесь необходимо рассмотреть проблему подготовки педагогических кадров. Только духовная и нравственная личность наставника способна заложить в воспитанника духовные и нравственные ценности.

Для каждого времени характерна своя культурно-образовательная среда (КОС) - место, где развивается человек, происходит взаимодействие обучающихся с преподавателями; место где соединяются культура и образование, теория и практика, среда и человек, духовность и нравственность, наследие и современность. Культурно-образовательная среда делает человека личностью культурной, гражданином, профессионалом, семьянином. Достижения современной науки, в том числе труды отечественных философов и психологов, педагогов и физиологов, юристов и генетиков, свидетельствуют о том, что только в социальной среде в процессе целенаправленного воспитания происходит становление человека как личности. Но любая среда должна строиться на 
фундаментальном наследии, для чего необходимо изучение педагогического краеведения.

Использование педагогических идей духовного наследия в современной педагогике необходимо. В нашей стране большое количество городов, деревень, сел, поселков со своей самобытностью, диалектом, с людьми, отличившимися в таких сферах жизни, как живопись, наука, музыка и литература и др.

Школа как центр живой культуры призвана обеспечить социальную и духовную зрелость подрастающего поколения. Решить эту задачу можно только при культурообразующем характере всего образовательновоспитательного процесса, в котором мы стремимся целостно и гармонично представить ценности материальной и духовной культуры, основы профессиональных технологий и ведущие сферы искусства, ремесла, экономическую культуру, правовую культуру, культуру труда и семейных отношений.

В процессе развития общества на современном этапе особую значимость приобретает духовная культура человека. Культура обладает свойством воздействовать на всю социальную сферу, общество уже давно признало благотворную роль общечеловеческих ценностей в формировании нравственных, духовных основ личности. В наиболее общем значении, культура - это исторически определенный уровень развития общества и человека, выраженный в формах организации жизнедеятельности людей, а также в созданных ими материальных и духовных ценностях. Это содержание понятия «культура» отражено на схеме, из которой видно, что по характеру культурных ценностей культуру разделяют на материальную и духовную. Именно проблемы воспитания духовной культуры выходит в настоящее время на первый план потому, что она охватывает деятельность сознания и эмоций человека и продукты 
духовного производства. Все это позволяет считать воспитание духовной культуры приоритетным направлением социального воспитания.

Рассмотрим одну из классификаций духовной культуры:

- по уровню применения - метатехнология на уровне государственной политики;

- по философской основе - гуманистическая технология, охватывающая разнообразные философские концепции;

- по ориентации на сферы развития личности - воспитательная технология, влияющая на все сферы личности;

- по концепции освоения опыта - технология, использующая все каналы и механизмы воздействия;

- по характеру содержания - проникающая технология;

- по организационным формам - технология, использующая все формы взаимодействия субъектов (от индивидуальной до массовой);

- по методам и средствам - технология, применяющая самый широкий диапазон таковых;

- по подходу к ребенку и воспитательной ориентации - личностно ориентированная технология;

- по категории - массовая.

В вопросах целеполагания данная технология выделяет позицию общества и позицию потребителя (детей, подростков и молодежи). С позиции интересов общества целями можно считать следующие:

- передавать, сохранять и развивать культуру общества;

- формировать разносторонне развитого человека;

- повышать культурный и образовательный уровень населения;

- транслировать опыт поколений и поддерживать народные и семейные традиции;

- формировать и поддерживать духовные, нравственные ценности, убеждения и модели поведения; 
- воспитывать гражданственность, патриотические чувства, мультикультурное сознание.

С позиции потребителей:

- помогать саморазвитию, самовоспитанию, самоопределению и самообразованию;

- оказывать помощь в жизненной самореализации и самоактуализации;

- удовлетворять и развивать нравственно-эстетические потребности;

- развивать творческую сферу личности.

Сегодня мы наблюдаем новый подход к рассмотрению духовной культуры, в основе которого лежат следующие положения:

1. Культура - основа социально-экономического подъема. Человек является созидателем культуры на принципах нравственности и духовности.

2. Интеграция традиций и инноваций в развитии общества.

3. Педагогическое наследие культурно-исторического, социальнопедагогического опыта и др..

4. Творчество - основа в решении всех жизненно важных задач.

В настоящее время актуализируется дискуссия по соотношению духовности нравственности в воспитании. С одной строны, духовность и восхождение к ней возможно, если личность имеет нравственный фундамент; с другой стороны, что духовность первична, поскольку духовный человек, уже несет в себе нравственность. Автор не берется утверждать и доказывать одну из этих точек зрения, в то же время отмечает, что все же в большей степени это зависит от понимания духовности и уровня освоения духовных ценностей, а так же подходов (светский и религиозный) и др.. Углубление в данную проблематику происходит в зависимости от общественных устоев, вектора развития общества и т.п.. 
В то же время мы считаем, что нравственность это общепринятое понятие в обществе, не отождествляемое с Истиной (божеством) и другими составляющими духовности. Но наличие такой категории как совесть имеет место и в нравственном воспитании и в духовном, да и не только совесть, например, любовь, терпение, милосердие и т.д. Обращаясь к современной действительности, наши наблюдения показывают, что человек с нравственными устоями, более готов к освоению духовных ценностей.

При воспитании, особенно в назидании, мы часто прибегаем к термину - совесть. Однако это понятие не стоит идеализировать, т.к. совесть может искажаться. Человеку присущи, помимо совести, разум, воля и т.П., и в зависимости от устремления человека, возможно доминирование над совестью, что приводит к ее искажению, становится «лукавой совестью». Часто на первый взгляд, доброе дело превращается во зло. Человек часто вступает в борьбу с совестью, доказывая себе и другим, оправдывая свои поступки, убеждая себя в правильности своего поступка. Есть и другой путь, когда человек относится к поступку легкомысленно. Характеризуя этот путь, Ильин пишет, что таким человеком «задачи не решаются, делается вид, что их вообще не существует» [4].

Совершая разные поступки, человек тем самым реализует определенную идентичность: семейную, профессиональную, нравственную и др. Так же идентичность бывает как субъективная, когда личность сама оценивает себя и объективная когда оценка происходит из окружения. Когда же идентичность длительное время не актуализируется, то происходит ее искажение, обесценивание или потеря.

Воспитание нравственных качеств личности основывается на понимании и освоении нравственных ценностей, составляющих общечеловеческую мораль. 
Цель образовательного учреждения заключается по нашему мнению в том, чтобы превратить образование из способа просвещения ребенка в механизм развития культуры, формирования образа мира и человека в нем. Основная миссия образования и воспитания заключается в формировании в ребенке, молодом человеке социальной ответственности, т.е. осознания того, что судьба мира находятся в руках человечества и конкретного человека (по В.С. Шадрикову).

Сегодня педагоги активно занялись патриотическим воспитанием подростающего поколения, акценты в котором делаются на военно патриотическом, краеведческом и гражданском составляющих. Это объясняется на наш взгляд тем, что мы еще никак не можем примириться с понятием духовности (сказывается атеистическое воспитание), а следовательно и принять. Это сложный и проблематичный вопрос. Принять, значит жить и совершать поступки в духовном контексте. Мы, несмотря на нашу нравственность, все же еще далеки от осознания духовности и своей миссии как духовной личности.

В каждом историческом периоде развития человечества есть своя специфическая иерархия ценностей культуры. Ценность как термин активно используется в контексте философии, социологии, педагогики, объясняя те или иные явления действительности. В то же время в любом из этих контекстов ценность выступает как эталон. Ценности являются регуляторами отношений человека к окружающей действительности и в то же время являются продуктом человеческой жизнедеятельности. Поэтому их можно разделить по видам: материальные, духовные, нравственные и др. и это объясняет многозначность понятия «ценность», различные подходы к изучению ценностей и их освоению. Освоение ценностей субъектом активно происходит когда он включается в социальную среду с характерными для нее ценностями, в культурно - образовательную среду, в микросреду. Субъект с одной стороны принимает среду, т.е. социально 
адаптируется и следовательно развивается, с другой стороны субъект влияет на среду. Таким образом, происходит взаимообогащение как субъекта, так среды. Если говорить о механизме освоения ценностей в микросреде (группе), то таким механизмом является социальная идентичность.

Говоря о принятии ценностей субъектом в контексте психологии, следует указать на то, что психология рассматривает эту проблему глубоко и многогранно. Существует большое количество работ в психологии, рассматривающих данную проблему. Так А. Маслоу писал: «Состояние бытия вне системы ценностей является психопатогенным. Человеческому существу, чтобы жить и постигать жизнь, необходимы системы координат, философия жизни... почти в той же мере, что и солнечный свет, кальций и любовь» [6].

Остановимся на педагогических ценностях.

Педагогические ценности по мнению В.А. Сластенина - это те ее особенности, которые позволяют не только удовлетворять потребности педагога, но и служат ориентирами его социальной и профессиональной активности, направленной на достижение гуманистических целей. Педагогические ценности зависят от социальных, политических, экономических отношений в обществе, которые во многом влияют на развитие педагогики и образовательной практики. С изменением социальных условий жизни, развитием потребностей общества и личности трансформируются и педагогические ценности. Педагогические ценности различаются по уровню своего существования. По этому основанию выделяются личностные, групповые и социальные педагогические ценности. Система ценностных ориентаций содержит не только когнитивные, но и эмоционально-волевые компоненты, играющие роль ее внутреннего ориентира. В ней ассимилированы как социальнопедагогические, так и профессионально-групповые ценности, служащие 
основанием индивидуально-личностной системы педагогических ценностей. Эта система включает:

- ценности, связанные с утверждением личностью своей роли в социальной и профессиональной среде (общественная значимость труда педагога, престижность педагогической деятельности, признание профессии ближайшим личным окружением и др.);

- ценности, удовлетворяющие потребность в общении и расширяющие его круг (общение с детьми, коллегами, референтными людьми, переживание детской любви и привязанности, обмен духовными ценностями и др.);

- ценности, ориентирующие на саморазвитие творческой индивидуальности

(возможности развития профессионально-творческих способностей, приобщение к мировой культуре, занятие любимым предметом, постоянное самосовершенствование и др.);

- ценности, позволяющие осуществить самореализацию (творческий, вариативный характер труда педагога, романтичность и увлекательность педагогической профессии, возможность помощи социально неблагополучным детям и др.);

- ценности, дающие возможность удовлетворять прагматические потребности (возможности получения гарантированной государственной службы, оплата труда и длительность отпуска, служебный рост и др.) [7].

В процессе индивидуального самосовершенствования, которое сопровождается постижением духовных ценностей, освоение которых и выделяет личность из сообществ. Личность, постигшая духовные ценности в большей степени готова к состраданию, содружеству, сотворчеству. Духовные ценности направлены против войн, и в то же время за защиту Отечества, вплоть до самопожертвования. Духовность это стержневая основа личности. Духовность - это «устремление человека к тем или иным 
высшим ценностям и смыслу, идеалу, стремление человека переделать себя, приблизить свою жизнь к этому идеалу и внутренне освободиться от обыденности» (В. И. Даль).

Особая роль в понимании духовности принадлежит русским философам конца XIX - начала XX века - А.С.Хомякову, В.Соловьеву, В.Розанову, Н.Страхову, Н.Бердяеву, П.Флоренскому, С.Булгакову и другим. По их мнению, это специфический способ личностного бытия.

Интересны мнения психологов В.И. Слободчикова и Е.И. Исаева которые рассматривают духовность как смысл жизни..... Духовность есть самая глубинная суть человека как родового существа. Человек представляется ими как существо природное, телесное, как сознательный индивид, как участник культурной жизни общества, как субъект творческой и сознательной деятельности. И это дает основание говорить о духовности как о закономерном состоянии человека [8].

Проанализировав взгляды на духовность отдельных исследователей, духовность можно рассматривать как высшую потребность человека в познании своей миссии, в стремлении к продолжению своей жизни в духовном плане (вечности), следовательно в выстраивании своих отношений с окружающим миром на принципах добра, любви, служения и Т.П.

Духовность можно разделить на внешнюю, соотносящуюся с социальным (мораль, развитие науки, техники и т.п.) и личную, включающую самосовершенствование, самосознание, собственную мыследеятельность и др.

И.А. Ильин рассматривал личную духовность как «вечный двигатель» социального, государственного, экономического, культурного строительства, как источник той силы, которая созидала Россию. Он особо подчеркивал, что личная духовность в России строила семью, воспитывала детей, вынашивала и выносила русское искусство, начиная от 
православной иконописи и кончая русской музыкой наших дней; создала русскую науку, нашла себе особое выражение в русской армии, проявлялась и в местном, сословном и церковном самоуправлении, в культурном (музыкальном, театральном и школьном) организаторстве, в хозяйственном творчестве русского крестьянина, купечества и дворянства [4].

В настоящее время, когда молодые люди поглощены материальными ценностями, необходимо обратить особое внимание на формирование духовных потребностей, творческих способностей на основе духовных ценностей. Поэтому сегодня преподаватели озадачены проблемами метапедагогического воспитания.

Рассмотрим алгоритм формирования духовных ценностей на основе модели формирования личных ценностей М.Р. Битяновой:

1. Проживание педагогом вместе с ребенком ценностное окрашенных ситуаций (жизненных, игровых).

2. Организация выделения их ценностного смысла для ребенка, ценностной квинтэссенции.

3. Стимулирование осознания ценностей ребенком и переформулирования их на язык своего опыта.

4. Проживание и получение личного опыта ценностного отношения и ценностных выборов в педагогически контролируемых ситуациях.

5. «Самостоятельная» жизнедеятельность ребенка с возможностью с помощью педагога специальных «рефлексивно-ценностных остановок к жизненным ситуациям».

Как видим, данная модель предполагает интерактивную деятельность субъекта.

Таким образом, функции образования многогранны и направлены как на подготовку новых поколений к самостоятельной жизни, 
развитие человека, так и на формирование образа человека. Формируя духовный, нравственный, интеллектуальный, культурный потенциал отдельной личности, мы тем самым способствуем развитию общества в конкретном контексте ценностей.

\section{Литература}

1. Александрова Е.А. Педагогическая поддержка культурного самоопределения как составляющая педагогики Свободы [Текст] /Е.А. Александрова - Саратов: изд-во СГУ, 2003. $200 \mathrm{c}$.

2. Белозерцев, Е.П. Культурно-образовательная среда Липецкой области: неизбежность изучения [Текст] / Е. П. Белозерцев // Материалы областной научнопрактической конференции «Региональный аспект в образовании и воспитании учащихся». - Липецк: ЛГИУУ; Елец: ЕГУ им. И.А. Бунина, 2003. - С. 7-14.

3. Домусчи С.А. Религиозная и нравственная идентичность в современном российском обществе [Текст] //А.В. Паршинцев Национально - культурная идентичность в современной России: истоки, особенности, перспективы - Санкт Петербург: изд-во Алетейя, 215. 592с.

4. Ильин И. А. О сопротивлении злу силою // Собр. соч.: В 10 т. Т. 5. М., 1996.

5. Козлова Т.А. Культурно-образовательная среда как условие становления и развития духовно-нравственной личности [Текст] / Т.А. Козлова //Материалы IX Международной научной конференции «Акмеология: личностное и профессиональное развитие человека» - Москва, 1-15 июня 2014 г.

6. Маслоу А. Самоактуализация людей: исследование психического здоровья. Курс практической психологии /А. Маслоу - М.: Психолог, 1992. - 354 с.

7. Педагогика: Учеб. пособие / В.А. Сластенин, И.Ф. Исаев, А.И. Мищенко, Е.Н. Шиянов. - М.: Школа-Пресс, 1998. - 512 с.

8. Слободчиков В.И., Исаев Е.И. / В.И. Слободчиков. Психология развития человека. - М.: Школьная пресса, 2000. -174 с.

\section{References}

1. Aleksandrova E.A. Pedagogicheskaja podderzhka kul'turnogo samoopredelenija kak sostavljajushhaja pedagogiki Svobody [Tekst] /E.A. Aleksandrova - Saratov: izd-vo SGU, 2003. $200 \mathrm{~s}$.

2. Belozercev, E.P. Kul'turno-obrazovatel'naja sreda Lipeckoj oblasti: neizbezhnost' izuchenija [Tekst] / E. P. Belozercev // Materialy oblastnoj nauchno-prakticheskoj konferencii «Regional'nyj aspekt v obrazovanii i vospitanii uchashhihsja». - Lipeck: LGIUU; Elec: EGU im. I.A. Bunina, 2003. - S. 7-14.

3. Domuschi S.A. Religioznaja i nravstvennaja identichnost' v sovremennom rossijskom obshhestve [Tekst] //A.V. Parshincev Nacional'no - kul'turnaja identichnost' v sovremennoj Rossii: istoki, osobennosti, perspektivy - Sankt - Peterburg: izd-vo Aletejja, 215. 592s.

4. Il'in I. A. O soprotivlenii zlu siloju // Sobr. soch.: V 10 t. T. 5. M., 1996.

5. Kozlova T.A. Kul'turno-obrazovatel'naja sreda kak uslovie stanovlenija i razvitija duhovno-nravstvennoj lichnosti [Tekst] / T.A. Kozlova //Materialy IX Mezhdunarodnoj nauchnoj konferencii «Akmeologija: lichnostnoe i professional'noe razvitie cheloveka» Moskva, 1-15 ijunja $2014 \mathrm{~g}$. 
6. Maslou A. Samoaktualizacija ljudej: issledovanie psihicheskogo zdorov'ja. Kurs prakticheskoj psihologii /A. Maslou - M.: Psiholog, 1992. - 354 s.

7. Pedagogika: Ucheb. posobie / V.A. Slastenin, I.F. Isaev, A.I. Mishhenko, E.N. Shijanov. - M.: Shkola-Press, 1998. - 512 s.

8. Slobodchikov V.I., Isaev E.I. / V.I. Slobodchikov. Psihologija razvitija cheloveka. M.: Shkol'naja pressa, 2000. -174 s. 